\title{
Correction to: Dietary intake of total polyphenols and the risk of all-cause and specific-cause mortality in Japanese adults: the Takayama study
}

\author{
Chie Taguchi $^{1} \cdot$ Yoshimi Kishimoto $^{1} \mathbb{D} \cdot$ Yoichi Fukushima $^{2} \cdot$ Kazuo Kondo $^{1,3} \cdot$ Michiyo Yamakawa $^{4} \cdot$ Keiko Wada $^{4}$. \\ Chisato Nagata ${ }^{4}$
}

Published online: 11 December 2019

(C) The Author(s) 2019

\section{Correction to: European Journal of Nutrition https://doi.org/10.1007/s00394-019-02136-9}

The original version of this article unfortunately contained a mistake. First sentence of the second paragraph of the section "Dietary and non-dietary assessments" should read as:

For the estimation of dietary total polyphenol intake, we used our original database of the polyphenol content of foods; the main values from this database are described elsewhere $[12,13]$.
Open Access This article is distributed under the terms of the Creative Commons Attribution 4.0 International License (http://creativeco mmons.org/licenses/by/4.0/), which permits unrestricted use, distribution, and reproduction in any medium, provided you give appropriate credit to the original author(s) and the source, provide a link to the Creative Commons license, and indicate if changes were made.

The original article can be found online at https://doi.org/10.1007/ s00394-019-02136-9.

Yoshimi Kishimoto

kishimoto.yoshimi@ocha.ac.jp

1 Endowed Research Department 'Food for Health',

Ochanomizu University, 2-1-1 Otsuka, Bunkyo-ku,

Tokyo 112-8610, Japan

2 Nestlé Japan Ltd, Tokyo, Japan

3 Faculty of Food and Nutritional Sciences, Toyo University, Gunma, Japan

4 Department of Epidemiology and Preventive Medicine, Gifu University Graduate School of Medicine, Gifu, Japan 